\title{
Advanced Coats' disease treated with intravitreal bevacizumab combined with laser vascular ablation
}

\author{
This article was published in the following Dove Press journal: \\ Clinical Ophthalmology \\ 16 May 2014 \\ Number of times this article has been viewed
}

\author{
Victor MVillegas' \\ Aaron S Gold' \\ Audina M Berrocal ${ }^{2}$ \\ Timothy G Murray' \\ 'Ocular Oncology and Retina, \\ Miami, FL, USA; '2Department of \\ Ophthalmology, Bascom Palmer Eye \\ Institute, Miller School of Medicine, \\ University of Miami, Miami, FL, USA
}

Purpose: To evaluate the impact of intravitreal bevacizumab combined with laser vascular ablation in the management of advanced Coats' disease presenting with exudative retinal detachment.

Methods: This was a retrospective review of 24 children that presented with exudative retinal detachments associated with advanced Coats' disease. Mean patient age was 62 months (range 9-160 months). Presenting signs included retinal detachment in 24 children (100\%), vascular telangiectasia in 24 children (100\%), and retinal ischemia in 24 children (100\%). Twenty of 24 children presented with elevated, vascular leakage in the fovea (83\%). Two children presented with sub-retinal fibrosis associated with presumed long-standing retinal detachment without evidence of rhegmatogenous retinal detachment. Ten patients exhibited vascular alterations in the periphery of the second eye without clinical evidence of exudation. All 24 children were treated with a large-spot-size diode laser directly to areas of abnormal telangiectatic vasculature. All 24 children received intravitreal bevacizumab injection.

Results: All 24 children had resolution of exudative retinal detachment, ablation of vascular telangiectasia, and anatomic improvement of the retina. No child exhibited progressive retinal detachment and no eye required enucleation. No cases of neovascular glaucoma were seen. Fellow eyes with peripheral vascular alterations showed no progression to exudative vasculopathy during the observation period. Intravitreal bevacizumab injection was not associated with endophthalmitis or systemically-observed complications.

Conclusion: Repetitive intravitreal bevacizumab combined with laser vascular ablation may be utilized effectively for advanced Coats' disease presenting with exudative retinal detachment.

Keywords: Coats' disease, bevacizumab, anti-VEGF, laser ablation, retina

\section{Introduction}

Coats' disease was first described in 1908 by Scottish ophthalmologist Georges Coats. ${ }^{1}$ This entity was characterized by unilateral retinal vascular abnormalities and retinal exudation in young males. In 1912, Leber described a disease with similar telangiectatic changes but without the massive exudation described by Coats. ${ }^{2}$ Reese merged the two diseases in a single spectrum that started as Leber disease but progressed to Coats' disease during long-term follow-up. ${ }^{3}$

Treatment of Coats' disease depends on the stage of the disease. Mild cases can be observed. ${ }^{4}$ However, if exudation, retinal, or subretinal fluid is present, treatment with laser ablation or cryotherapy is necessary to areas of retinal telangiectasia and retinal nonperfusion. ${ }^{5}$ Surgery may be needed in cases of nonclearing vitreous hemorrhage or severe retinal detachment.

Intravitreal anti-vascular endothelial growth factor (VEGF) has been reported to be effective as adjunctive therapy to reduce subretinal fluid and exudation both alone
Correspondence:Timothy G Murray Murray Ocular Oncology and Retina, 6705 Red Road, Suite 4I2, Miami, FL 33|43, USA

Email tmurray@murraymd.com 
and in combination with other treatment modalities. ${ }^{6-10}$ The purpose of our study is to evaluate the impact of repetitive intravitreal bevacizumab combined with laser vascular ablation in the management of advanced Coats' disease presenting with exudative retinal detachment.

\section{Methods}

A retrospective review of all patients with Coats' disease diagnosed and treated with intravitreal bevacizumab by the same senior clinician (TGM) was conducted. Patient age, sex, date of presentation, date of last follow-up, number of laser and bevacizumab application sessions, presenting stage of Coats' disease, and final stage of Coats' disease were recorded. Exclusion criteria for treatment included patients whose social situations prevented them from receiving ongoing care, and patients who presented with no light perception, and thus were observed without receiving laser treatment.

Patients with advanced Coats' disease were treated with laser ablation applied at each clinical visit to all areas of retinal telangiectasis and/or exudative retinal detachment (Figures 1 and 2). Patients underwent examinations under anesthesia approximately every 2 months while treatment was continued. Laser treatments were continued until either complete anatomic resolution of exudation and telangiectasis was achieved or until neovascular glaucoma and no light perception vision developed and treatment was no longer deemed to be helpful.
Laser therapy was delivered while patients were under anesthesia using the $810 \mathrm{~nm}$ iris diode laser (IRIDEX Corporation, Mountain View, CA, USA). The $1.2 \mathrm{~mm}$ spot size was aimed through a dilated pupil using the indirect ophthalmoscope and a 20-diopter lens. The laser was generally set at a power of $350 \mathrm{~mW}$. The entire surface of telangiectatic vessels and/or exudative detachment was treated. The clinical endpoint was the complete whitening of the telangiectatic vessels. Treatment was also applied to the avascular retinal areas peripheral to telangiectatic vessels. Intravitreal bevacizumab $1.25 \mathrm{mg}$ was injected in the pars plana consecutively in all patients.

\section{Results}

Twenty-four children presented with exudative retinal detachment associated with advanced Coats' disease. Mean patient age was 62 months (range 9-160 months). Seventeen children were boys (71\%), and 7 were girls. Presenting signs included retinal detachment in 24 children $(100 \%)$, vascular telangiectasia in 24 children $(100 \%)$, and retinal ischemia in 24 children (100\%). Twenty of 24 children presented with elevated, vascular leakage in the fovea $(83 \%)$. Two children presented with sub-retinal fibrosis associated with presumed long-standing retinal detachment without evidence of rhegmatogenous retinal detachment. Ten patients exhibited vascular alterations in the periphery of the second eye without clinical evidence of exudation. All 24 children were treated with a large-spot-size diode laser in areas of abnormal

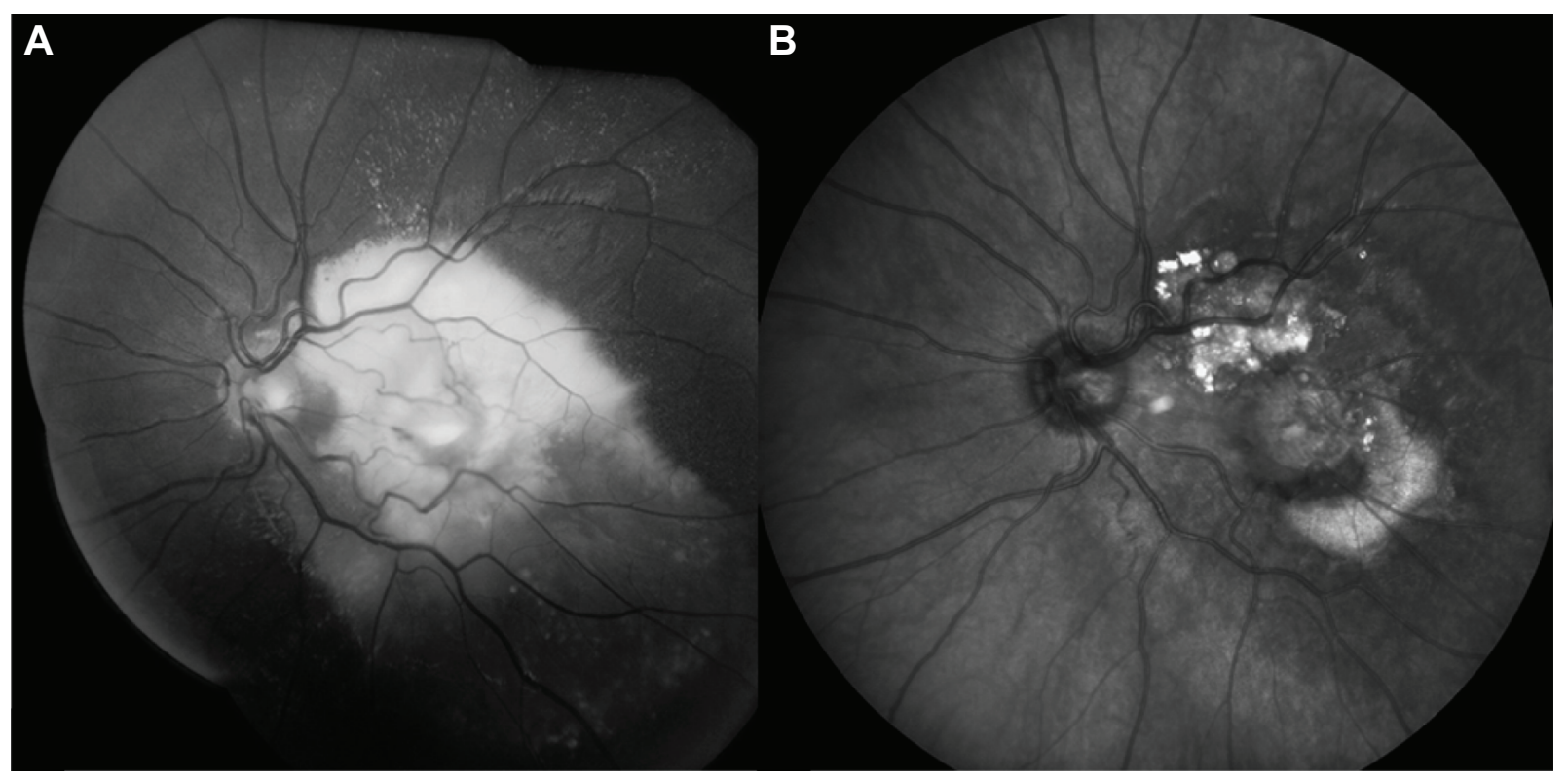

Figure I The patient has a total (fovea-involving) exudative retinal detachment. Notes: Fundus photograph of patient one at presentation (A). After treatment (B). 


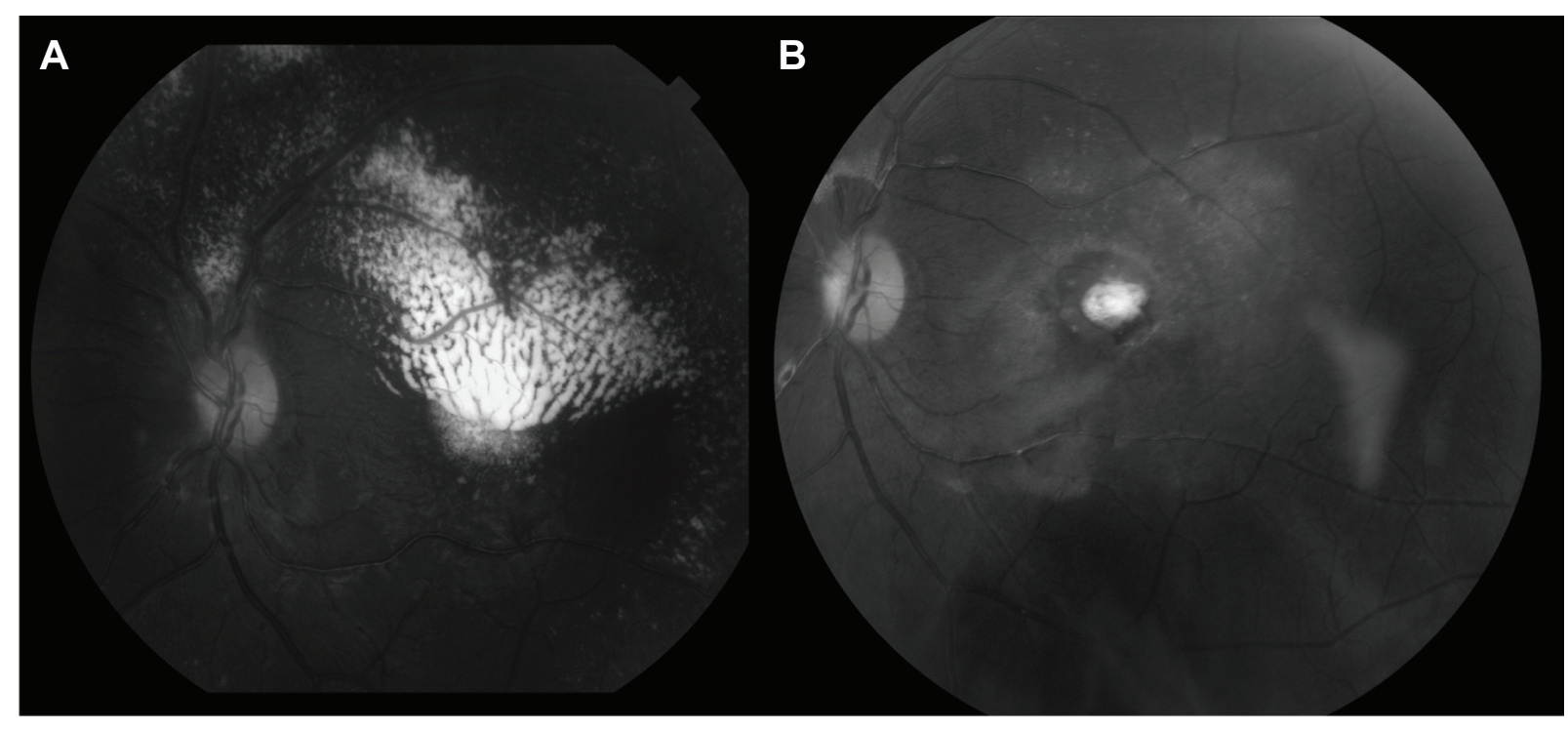

Figure 2 The patient has massive subretinal exudation with a hemiretinal distribution in the macula.

Notes: Fundus photograph of patient two at presentation (A). After treatment (B).

telangiectatic vasculature. All 24 children received intravitreal bevacizumab injection. Mean number of laser treatment sessions was 7.4 (range 3-15 sessions) while mean number of intravitreal injections was 4.6 (range 2-9 injections). Mean patient follow-up was 22.4 months (range 6-36 months). All 24 children had resolution of exudative retinal detachment, ablation of vascular telangiectasia, and anatomic improvement of the retina. No child exhibited progressive retinal detachment and no eye required enucleation. No cases of neovascular glaucoma were seen. Fellow eyes with peripheral vascular alterations showed no progression to exudative vasculopathy during the observation period. Intravitreal bevacizumab injection was not associated with endophthalmitis or systemically-observed complications.

\section{Discussion}

The treatment of Coats' disease has included the multiple modalities of observation, laser, cryotherapy, surgical management, and enucleation in cases of painful blind eyes. ${ }^{5}$ The mainstay of treatment remains laser ablation.

A recent study by Zhao et al has shown that the VEGF concentrations correlated with the severity of Coats' disease. ${ }^{11}$ VEGF concentrations significantly correlated with extent of exudative retinal detachment. Other authors have also found elevated levels of VEGF in patients with Coats' disease. ${ }^{12-14}$ Marked reduction in VEGF levels and improvement of exudation and retinal detachment have been seen in association with treatment with anti-VEGF agents. ${ }^{15}$

In most available case reports of Coats' disease treated with bevacizumab, VEGF appears to be well-tolerated.
However, case numbers are small with limited follow-up. In our study, all patients had resolution of retinal detachment and anatomic improvement of the retina. Follow-up was unremarkable and without complications.

Anti-VEGF appears to be safe. ${ }^{7-10}$ However, a retrospective analysis of eight patients with Coats' disease manifesting total or partial exudative retinal detachment where the retinal telangiectasia was treated with standard laser photocoagulation and/or cryotherapy plus additional intravitreal bevacizumab showed that treatment with intravitreal bevacizumab in addition to standard therapy can be associated with vitreoretinal fibrosis. ${ }^{15}$ Longer follow-up and larger studies will be necessary to establish safety of bevacizumab in Coats' disease.

Weaknesses in this study include small sample size and nonrandomization. Additionally, achieving statistical superiority of laser ablation plus intravitreal bevacizumab over laser ablation alone carries intrinsic difficulties due to the rare nature of this disease. Furthermore, several authors have reported exudative recurrences after 10 years of initial laser ablation, making long-term assessment difficult. ${ }^{4,16}$ Extended serial follow-up will be important for these patients to ensure that good outcomes can be sustained over time.

\section{Conclusion}

The goal of this study was to evaluate the efficacy of repetitive intravitreal bevacizumab combined with laser vascular ablation in the management of advanced Coats' disease presenting with exudative retinal detachment. We found that this approach resulted in resolution of retinal detachment in 
all cases. Although this is a small patient series, our study results are promising and should be explored further with an enlarged cohort. We advise against intravitreal injection in all cases in which the diagnosis of retinoblastoma is uncertain.

\section{Disclosure}

The authors declare no conflicts of interest in this work.

\section{References}

1. Coats G. Forms of retinal disease with massive exudation. $R$ Lond Ophthalm Hosp Rep. 1908;525:440-525.

2. Leber T. Ueber eine durch Vorkommen multipler Miliaraneurysmen charakterisierte Form von Retinaldegeneration. Albrecht von Graefe's Arch Klin Ophthalmol. 1912;81:1-14. German.

3. Reese AB. Telangiectasis of the retina and Coats' disease. Am J Ophthalmol. 1956;42:1-8.

4. Shields JA, Shields CL, Honavar SG, Demirci H. Clinical variations and complications of Coats' disease in 150 cases: the 2000 Sanford Gifford Memorial Lecture. Am J Ophthalmol. 2001;131:561-571.

5. Schefler AC, Berrocal AM, Murray TG. Advanced Coats' disease. Management with repetitive aggressive laser ablation therapy. Retina. 2008;28(Suppl 3):S38-S41.

6. Sisk RA, Berrocal AM, Albini TA, Murray TG. Ophthalmic Surg Lasers Imaging. 2010;41(6):582-592.

7. Ray R, Barañano DE, Hubbard GB. Treatment of Coats' disease with intravitreal bevacizumab. Br J Ophthalmol. 2013;97(3):272-277.
8. Böhm MR, Uhlig CE. Use of intravitreal triamcinolone and bevacizumab in Coats' disease with central macular edema. Graefes Arch Clin Exp Ophthalmol. 2011;249(7):1099-1101.

9. Lin CJ, Hwang JF, Chen YT, Chen SN. The effect of intravitreal bevacizumab in the treatment of Coat's disease in children. Retina. 2010;30(4):617-622.

10. Entezari M, Ramezani A, Safavizadeh L, Bassirnia N. Resolution of macular edema in Coats' disease with intravitreal bevacizumab. Indian J Ophthalmol. 2010;58(1):80-82.

11. Zhao Q, Peng XY, Chen FH, et al. Vascular endothelial growth factor in Coats' disease. Acta Ophthalmol. 2014;92(3):e225-e228.

12. Sun Y, Jain A, Moshfeghi DM. Elevated vascular endothelial growth factor levels in Coats' disease: rapid response to pegaptanib sodium. Graefes Arch Clin Exp Ophthalmol. 2007;245:1387-1388.

13. Kase S, Rao NA, Yoshikawa H, et al. Expression of vascular endothelial growth factor in eyes with Coats' disease. Invest Ophthalmol Vis Sci. 2013;54(1):57-62.

14. He YG, Wang H, Zhao B, Lee J, Bahl D, McCluskey J. Elevated vascular endothelial growth factor level in Coats' disease and possible therapeutic role of bevacizumab. Graefes Arch Clin Exp Ophthalmol. 2010;248(10):1519-1521.

15. Ramasubramanian A, Shields CL. Bevacizumab for Coats' disease with exudative retinal detachment and risk of vitreoretinal traction. $\mathrm{Br}$ J Ophthalmol. 2012;96(3):356-359.

16. Shienbaum G, Tasman WS. Coats' disease: a lifetime disease. Retina. 2006;26(4):422-424.
Clinical Ophthalmology

\section{Publish your work in this journal}

Clinical Ophthalmology is an international, peer-reviewed journal covering all subspecialties within ophthalmology. Key topics include: Optometry; Visual science; Pharmacology and drug therapy in eye diseases; Basic Sciences; Primary and Secondary eye care; Patient Safety and Quality of Care Improvements. This journal is indexed on

\section{Dovepress}

PubMed Central and CAS, and is the official journal of The Society of Clinical Ophthalmology (SCO). The manuscript management system is completely online and includes a very quick and fair peer-review system, which is all easy to use. Visit http://www.dovepress.com/ testimonials.php to read real quotes from published authors. 